\title{
Impact of Pain on Stroke and Hypertension as Comorbidities In Parkinson's Disease
}

\author{
Vincent Ongko Wijaya*, Rizaldy Taslim Pinzon, Abraham Al Jody \\ Faculty of Medicine, Duta Wacana Christian University, Indonesia
}

*Corresponding author: Vincent Ongko Wijaya, Faculty of Medicine Duta Wacana Christian University, Dr. Wahidin Sudirohusodo street number 5-25 Yogyakarta 55224, Indonesia

To Cite This Article: Vincent Ongko W, Rizaldy Taslim P, Abraham Al J. Impact of Pain on Stroke and Hypertension as Comorbidities In Parkinson's Disease. Am J Biomed Sci \& Res. 2019 - 1(2). AJBSR.MS.ID.000519. DOI: 10.34297/AJBSR.2019.01.000519

Received: January 30, 2019 | Published: February 05, 2019

\begin{abstract}
Purpose: Pain is one of the most common non-motor symptom of Parkinson's Disease (PD) and related to disability, while the presence of comorbidity can deteriorate patient's quality of life. The relationship between pain and comorbidity in PD has not been clearly explored. Understanding pain and patient comorbidity especially stroke and hypertension is crucial in the management of PD.
\end{abstract}

Objectives: This study aimed to report the prevalence and type of pain in patient with PD, and to determine the relationship between each type of pain and comorbidities (stroke and hypertension).

Methods: This was a cross sectional study design. Data obtained from questionnaire filled by patients and hospital data registry at Bethesda Hospital, Yogyakarta. Pain was assessed using King's Parkinson's Disease Pain Scale (KPPS) questionnaire. Data were analysed descriptively and chi-square test for the pain correlation.

Results: Thirty-one PD patients were recruited for this study, and most subjects were $>70$ years old (45.1\%). Pain was present in over 22 patients (70.96\%) consisted of 13 male (59.1\%) and 9 females (40.9\%). 20 subjects (64.5\%) were in stage III Hoehn and Yahr as the most common severity level of disease. Stroke (74.2\%) was more common than hypertension (38.7\%) in PD patient. Musculoskeletal pain (45.2\%) was the most common type of pain in PD patients and significantly correlate with stroke $(45.2 \%, \mathrm{p}<0.05)$, and orofacial pain $(0 \%)$ as the least common type of pain. Chronic pain was also correlated with hypertension $(16.1 \%, \mathrm{p}<0.05)$.

Conclusion: Pain is a frequent complaint in PD. Furthermore, some types of pain were correlated with stroke as well as hypertension as comorbidities in PD.

Keywords: Pain; Parkinson's disease; Comorbidity; Stroke; Hypertension

\section{Introduction}

Parkinson's Disease (PD) is the second most common neurodegenerative disease in the world after Alzheimer's Disease. Approximately, 5 million people around the world suffers from PD [1]. Non-motor symptoms of PD are found in all stages of PD and have a significant role in the impairment of quality of life. Previous study showed that non-motor symptoms of PD are frequently underdiagnosed by clinician [2]. In the early development of PD, Pain was one of the most disturbing symptoms, yet it is still poorly understood. The prevalence rate of pain in PD was estimated to be $60 \%$ and was an early sign of development of PD even precedes the motor symptoms in the early years of the disease [3-5].

Persistent pain is highly prevalent and frequently causing disability in later life. It is most often linked to musculoskeletal causes, which involves multiple locations, and often occurs with other comorbidities [6].

$\mathrm{PD}$ is a progressive neurodegenerative disease that increases in prevalence with age. While high rates of individual comorbidities in people with PD have been reported, only few studies have systematically analysed the presence of multiple-system comorbidity in association to mobility. In other studies, comorbidity has been a predictor of mortality and negative clinical outcomes after hip fracture and acute myocardial infarction in the elderly. Some studies suggest that comorbidities are linked to increased risk of mortality in persons with PD [7-9].

Pain is a common complication after stroke and is associated with the presence of cognitive dysfunction, and impaired quality 
of life. It frequently underdiagnosed and undertreated, despite the evidence that effective pain treatment may help improve function and increases quality of life. Previous studies also revealed the relationship between hypertension and PD, HT is associated with a more severe stages of PD, suggest that an optimal management of HT may help with PD symptoms $[10,11]$. Although, PD has been associated with stroke and also hypertension. the relationship between pain as non-motor symptom in PD and hypertension as well as stroke, remains unclear. In this study, we presented the prevalence of pain in PD and the relationship between type of pain and stroke as well as hypertension as comorbidities in PD patients.

\section{Method}

\section{Study design}

A cross sectional study was carried out from January 2018 to March 2018, 31 PD patients were recruited from the neurology department in Bethesda Hospital Yogyakarta using consecutive sampling. Subjects with inability to communicate well (e.g. history of dementia, aphasia) were excluded from this study. All subjects took their routine anti-parkinson medication (e.g. levodopa, pramipexole) for the PD medication as normally indicated. Written informed consent was obtained from all the subjects before the procedure began in accordance to the research guideline. This study has been approved by the Ethical Committee of Duta Wacana Christian University School of Medicine, protocol number 547/C.16/FK/2017.

\section{Data analysis}

In the statistical analyses, subjects' characteristics were analysed for descriptive statistics, including proportion of age, sex, and severity of the disease. Types and prevalence of pain were also reported descriptively. Bivariate analysis with chi-square was used to assess the relationship between type of pain and stroke as well as hypertension as comorbidities in PD patients. In this study SPSS software 21.0 was used for all statistical analyses. Statistical significance was measured at $\mathrm{p}<0.05[10,11]$.

\section{Pain assessment}

Pain was assessed using KPPS. This specific pain scale questionnaire has been validated to classify and assess various types of pain in PD patients. There are 14 questions consisted of 7 domains, each domain represented different subtype of pain modality: (1) musculoskeletal pain; (2) chronic pain; (3) fluctuation-related pain; (4) nocturnal pain; (5) oro-facial pain; (6) Discoloration, edema/swelling; and (7) radicular pain. Each Item scored by severity (0-3) multiplied by frequency (0-4), resulting in a subscore range from 0 to 12 , with a total possible score range from 0 to 168 . The KPPS time frame is to assessed pain in the past month. For this study, we used this instrument to classify different types of pain in PD patients. The prevalence of each pain symptom assessed by the KPPS was calculated by considering an item score $\geq 1$ to be the presence of that symptom and an item score of zero to be its absence. Furthermore, patients were divided into groups using the prevalence of each of the seven pain modalities (domains) assessed by the KPPS [9].

\section{Comorbidities assessment}

Comorbidities assessed in this study included hypertension and stroke. Hypertension was diagnosed based on the Joint National Committee on Prevention, Detection, Evaluation, and Treatment of High Blood Pressure- 8 (JNC 8) criteria. Hypertension was defined as systolic blood pressure $\geq 140 \mathrm{mmHg}$ or diastolic blood pressure $\geq 90 \mathrm{mmHg}$ or consuming antihypertensive drugs or written in medical records. Cerebrovascular disease or stroke was diagnosed based on brain CT scan, interpreted by a neurologist or radiologist or written in medical records. Either subjects with history of ischemic or haemorrhagic stroke, both were interpreted as stroke in this study. Based on each comorbidity, subjects were differentiated into subjects with or without stroke and with or without hypertension.

\section{Results}

Thirty-one PD patients were enrolled for this study. Majority of the patients were $>70$ years old (45.1\%), most of them are males (54.8\%), and the most common severity level of disease was stage III Hoehn \& Yahr (64.5\%). As for the comorbidities, stroke (74.2\%) was more common than hypertension (38.7\%) in PD patients (Table 1).

\begin{tabular}{|c|c|c|}
\hline $\begin{array}{c}\text { Clinical } \\
\text { Characteristics }\end{array}$ & $n=31$ & $\%$ \\
\hline \multicolumn{3}{|c|}{ Age (years) } \\
\hline $40-50$ & 1 & 3.3 \\
\hline $51-60$ & 3 & 9.7 \\
\hline $61-70$ & 13 & 41.9 \\
\hline$>70$ & 14 & 45.1 \\
\hline \multicolumn{3}{|c|}{ Sex } \\
\hline Male & 17 & 54.8 \\
\hline Female & 14 & 45.2 \\
\hline \multicolumn{3}{|c|}{ Stage (H\&Y) } \\
\hline I & 0 & 0 \\
\hline II & 9 & 29 \\
\hline III & 20 & 64.5 \\
\hline IV & 2 & 6.5 \\
\hline $\mathrm{V}$ & 0 & 0 \\
\hline \multicolumn{3}{|c|}{ Comorbidities } \\
\hline \multicolumn{3}{|l|}{ Stroke } \\
\hline Yes & 23 & $74.20 \%$ \\
\hline No & 8 & $25.80 \%$ \\
\hline \multicolumn{3}{|c|}{ Hypertension } \\
\hline Yes & 12 & $38.70 \%$ \\
\hline No & 19 & $61.30 \%$ \\
\hline
\end{tabular}




\begin{tabular}{|c|c|c|}
\hline Types of Pain & $n=31$ & $\%$ \\
\hline \multicolumn{3}{|c|}{ Domain 1} \\
\hline Musculoskeletal pain & 14 & 45.2 \\
\hline \multicolumn{3}{|c|}{ Domain 2} \\
\hline Chronic pain & 5 & 16.1 \\
\hline \multicolumn{3}{|c|}{ Domain 3} \\
\hline Fluctuation-related pain & 2 & 6.5 \\
\hline \multicolumn{3}{|c|}{ Domain 4} \\
\hline Nocturnal pain & 8 & 25.8 \\
\hline \multicolumn{3}{|l|}{ Domain 5} \\
\hline Oro-facial pain & 0 & 0 \\
\hline \multicolumn{3}{|c|}{ Domain 6} \\
\hline Discoloration, oedema/swelling & 6 & 19.4 \\
\hline \multicolumn{3}{|c|}{ Domain 7} \\
\hline Radicular pain & 8 & 25.8 \\
\hline
\end{tabular}

There were different types of pain in patients with PD. Pain was present in over 22 patients (70.96\%). The most common type of pain in PD patients was musculoskeletal pain with 14 patients (45.2\%), followed by nocturnal pain (25.8\%), radicular pain (25.8\%), discoloration associated with oedema/swelling $(19.4 \%)$, chronic pain (16.1\%), fluctuation-related pain $(6.5 \%)$ and the least was oro-facial pain $(0 \%)$ (Table 2 ).

This study presented the relationship between pain types and stroke as well as hypertension. Based on different types of pain, revealed that the presence of musculoskeletal pain was correlated with stroke (OR: 0.18; 95\% CI: 0.03-1.09; p=0.04, Chi-square test) (Table 3). Another type of pain also related with hypertension. Statistical analysis revealed that the presence of chronic pain was correlated with hypertension (OR: 3.71; 95\% CI: 1.97-6.99; p=0.02, Chi-square test) (Table 4). In this study, the presence of other types of pain were not statistically significant with stroke as well as hypertension $(p>0.05)$.

\begin{tabular}{|c|c|c|c|c|c|}
\hline Types of Pain & With Stroke & Without Stroke & OR & $95 \% \mathrm{CI}$ & p-value \\
\hline \multicolumn{6}{|c|}{ Domain 1} \\
\hline Musculoskeletal pain & $8(25.8 \%)$ & $6(19.4 \%)$ & 0.18 & $0.03-1.09$ & $0.04^{*}$ \\
\hline \multicolumn{6}{|c|}{ Domain 2} \\
\hline Chronic pain & $4(12.9 \%)$ & $1(3.2 \%)$ & 1.47 & $0.14-15.55$ & 0.75 \\
\hline \multicolumn{6}{|c|}{ Domain 3} \\
\hline $\begin{array}{l}\text { Fluctuation-related } \\
\text { pain }\end{array}$ & $1(3.2 \%)$ & $1(3.2 \%)$ & 0.32 & $0.02-5.78$ & 0.42 \\
\hline \multicolumn{6}{|c|}{ Domain 4} \\
\hline Nocturnal pain & $6(19.4 \%)$ & $2(6.5 \%)$ & 1.06 & $0.17-6.74$ & 0.95 \\
\hline \multicolumn{6}{|c|}{ Domain 6} \\
\hline $\begin{array}{l}\text { Discoloration, edema/ } \\
\text { swelling }\end{array}$ & $3(9.7 \%)$ & $3(9.7 \%)$ & 0.25 & $0.04-1.63$ & 0.13 \\
\hline \multicolumn{6}{|c|}{ Domain 7} \\
\hline Radicular pain & $4(12.9 \%)$ & $4(12.9 \%)$ & 0.21 & $0.04-1.22$ & 0.07 \\
\hline
\end{tabular}

\begin{tabular}{|c|c|c|c|c|c|}
\hline Types of pain & $\begin{array}{c}\text { With } \\
\text { Hypertension }\end{array}$ & $\begin{array}{c}\text { Without } \\
\text { Hypertension }\end{array}$ & OR & $95 \% \mathrm{CI}$ & p-value \\
\hline \multicolumn{6}{|c|}{ Domain 1} \\
\hline Musculoskeletal pain & $7(22.6 \%)$ & $17(22.6 \%)$ & 2.4 & $0.55-10.53$ & 0.24 \\
\hline \multicolumn{6}{|c|}{ Domain 2} \\
\hline Chronic pain & $5(16.1 \%)$ & $0(0 \%)$ & 3.71 & $1.97-6.99$ & $0.02^{*}$ \\
\hline \multicolumn{6}{|c|}{ Domain 3} \\
\hline $\begin{array}{l}\text { Fluctuation-related } \\
\text { pain }\end{array}$ & $1(3.2 \%)$ & $1(3.2 \%)$ & 1.64 & $0.09-28.90$ & 0.73 \\
\hline \multicolumn{6}{|c|}{ Domain 4} \\
\hline Nocturnal pain & $2(6.5 \%)$ & $6(19.4 \%)$ & 0.43 & $0.07-2.62$ & 0.36 \\
\hline \multicolumn{6}{|c|}{ Domain 6} \\
\hline $\begin{array}{l}\text { Discoloration, edema/ } \\
\text { swelling }\end{array}$ & $2(6.5 \%)$ & $4(12.9 \%)$ & 0.75 & $0.12-4.89$ & 0.76 \\
\hline \multicolumn{6}{|c|}{ Domain 7} \\
\hline Radicular pain & $3(9.7 \%)$ & $5(16.1 \%)$ & 0.93 & $0.18-4.90$ & 0.93 \\
\hline
\end{tabular}




\section{Discussion}

This study presented that $22 \mathrm{PD}$ patients $(71.2 \%)$ were in pain at the time of tested. Prevalence of pain in PD patients is frequent, occurring from 30 to $85 \%$ of patients [12-15]. Other study also stated that the pain prevalence varies from $34 \%$ to $83 \%$. The difference between the ranges of pain prevalence depend on the method that is used $[3,12]$. All the PD patients have received routine anti-Parkinson medication at the time of tested. According to the previous study, 94\% of PD patients took prescribed medicines as treatment for the disease [14].

Most of the PD patients are $>70$ years old, which supports the previous study that stated PD occurrence is directly proportional to age progression [16]. Among the subjects, male gender is predominantly found. Males were 1.5 to 2 times more susceptible to PD [16]. However, this finding was not similar in other studies, which shows female predominance [15]. This difference could be related to other factors, such as different sample size and subjective nature of the pain itself [16]. The most common severity level of the disease was stage III Hoehn \& Yahr. This result is similar with the previous studies, which shows that stage III of Hoehn \& Yahr PD severity assessment is more generally found in PD patients [1518]. Stroke is the most commonly found comorbidity among the subjects. This result is similar with the previous study, that found stroke is more commonly found than hypertension [18].

The results in this study showed the most common type of pain in PD based on KPPS, in order, is domain 1, Musculoskeletal pain (45.2\%); followed with domain 4, Nocturnal pain (25.8\%); domain 7, Radicular pain (25.8\%); domain 6, Discoloration, edema/ swelling (19.4\%); domain 2, Chronic pain (16.1\%); domain 3, Fluctuation-related pain (6.5\%); and domain 5, Oro-facial pain (0 $\%)$. This data was similar with previous study about KPPS, where the most common type of pain was musculoskeletal pain $(80.1 \%)$, followed by radicular pain (25.3\%) in comparison with the controls $(\mathrm{p}<0.05)[13,19]$.

From this study, it is revealed that the presence of musculoskeletal pain in PD patients was correlated with stroke. Various factors contribute to the occurrence of the musculoskeletal pain, in relation to the underlying stroke, such as psychological, central and peripheral mechanisms, and autonomic input [20]. Previous study found that musculoskeletal pain was highly occurred in acute, sub-acute, and chronic stage of stroke [20]. Another study also stated that the stroke-related pain could be explained by the mechanism of NLRP3 inflammasome, by injuring the cerebral cortex, which eventually increasing the excitability of ventral basal neurons; and through creating lesion in thalamus, complimented with strengthening the inflammatory response of the microglia's [21].

Statistical analysis revealed that the presence of chronic pain was correlated with hypertension. Previous study had found that decreased sensitivity to acute pain is associated with higher blood pressure [22]. In patients with chronic pain, an impairment in autonomic regulation, that involves baroreceptors and pain sensitivity, might be occurred [23].

\section{Conclusion}

Pain is a common non-motor symptom of PD and present in $70.96 \%$ of the subjects. Patients that are 70 years old and older are found mostly in this study, with $45.1 \%$. As much as $64.5 \%$ of total subjects were in stage III Hoehn and Yahr. Stroke (74.2\%) was more common than hypertension (38.7\%) in PD patient. Musculoskeletal pain (45.2\%) was the most common type of pain in PD patients and significantly correlate with stroke $(45.2 \%, \mathrm{p}<0.05)$, while orofacial pain $(0 \%)$ as the least common type of pain. Chronic pain was also correlated with hypertension $(16.1 \%, \mathrm{p}<0.05)$. This study showed that some types of pain were correlated with stroke as well as hypertension in PD.

\section{Acknowledgments}

All authors contributed toward data analysis, drafting and revising the paper, gave final approval of the version to be published and agree to be accountable for all aspects of the work.

\section{References}

1. Hauser S, Josephson S (2013) Harrison's neurology in clinical medicine. Mc-Graw Hill, $3^{\text {rd }}$ edn, New York, USA, pp. 333.

2. Chaudhuri K, Schapira H (2009) Non-motor symptoms of Parkinson's disease: dopaminergic pathophysiology and treatment Lancet Neural (8): 464-474.

3. Beiske G, Loge H, Rønningen A, Svenson E (2009) Pain in Parkinson's disease: prevalence and characteristics. Pain 141(1-2): 173-177.

4. Chaudhuri K, Prieto Jurcynska C, Naidu Y (2010) The no declaration of non-motor symptoms of Parkinson's disease to health care professionals: an international study using the nonmotor symptoms questionnaire. Mov Disord (25): 704-709.

5. Zis P, Erro R, Walton C, Sauerbier A, Chaudhuri K (2015) The range and nature of non-motor symptoms in drug-naive Parkinson's disease patients: a state-of-the-art systematic review. npj Parkinson's Disease (1): 15013.

6. Makris UE, Abrams RC, Gurland B, Reid MC (2014) Maagement of Persistent Pain in the Older Patient. JAMA 312(8): 825.

7. Yang XD, Zhao YS, Li YF, Guo XH (2011) Medical comorbidities at admission is predictive for 30-day in-hospital mortality in patients with acute myocardial infarction: analysis of 5161 cases. Journal of Geriatric Cardiology 8(1): 31-34.

8. Radosavljevic N, Lazovic M, Nikolic D, Petronic I, Radosavljevic Z, et al. (2012) Influence of selective comorbidity predictors on functional recovery after hip fracture in an older population. Biomed Pap Med Fac Univ Palacky Olomouc Czech Repub 156(4): 365-370.

9. Chaudhry S, Jin L, Meltzer D (2005) Use of a self-report-generated Charlson Comorbidity Index for predicting mortality. Med Care 43(6): 607-661.

10. Harrison RA, Field TS (2015) Post Stroke Pain: Identification, Assessment, and Therapy. Cerebrovasc Dis 39(3-4): 190-201.

11. B Giordano, G Pagano, J Hoon, N Ferrara, M Politis (2017) Hypertension and Parkinson's Disease. Mov Disord 32(2). 
12. Roh JH, Kim BJ, Jang JH (2009) Relationship of pain and health-related quality of life in Korean patients with Parkinson's disease. Acta Neurologica Scandinavia 119(6): 397-403.

13. Rizos M, Martinez Martin P, Pal S (2016) A Multicentre Study of The Patient's Perspective: The First Parkinson's Disease Pain Questionnaire (King's PD Pain Quest). The International Parkinson and Movement Disorder (30).

14. Wong SL, Gilmour H, Ramage Morin (2014) PL: Parkinson's disease: Prevalence, diagnosis and impact. Health Reports 25(11): 10-14.

15. Valkovic P, Minar M, Singliarova H (2015) Pain in Parkinson's Disease: A Cross-Sectional Study of Its Prevalence, Types, and Relationship to Depression and Quality of Life. PLoS One 10(8): e0136541.

16. Abbas MM, Xu Z, Tan LCS (2017) Epidemiology of Parkinson's DiseaseEast Versus West. Mov Disord Clin Pract 5(1): 14-28.

17. Tanveer K, Attique I, Sadiq W, Ahmad (2018) A Non-motor Symptoms in Patients with Parkinson's Disease: A Cross-sectional Survey. Cureus 10(10): e3412.
18. Wang X, Zeng F, Jin WS (2017) Comorbidity burden of patients with Parkinson's disease and Parkinsonism between 2003 and 2012: A multicentre, nationwide, retrospective study in China. Scientific Reports $7(1): 1671$.

19. Mylius V, Ciampi de Andrade D, Cury RG (2015) Pain in Parkinson's Disease: Current Concepts and a New Diagnostic Algorithm. Mov Disord Clin Pract 2(4): 357-364.

20. S Paolucci, M Iosa, D Toni, P Barbanti, P Bovi, et al. (2016) Prevalence and Time Course of Post-Stroke Pain: A Multicentre Prospective HospitalBased Study. Pain Medicine 17(5): 924-930.

21. Li SJ, Zhang YF, Ma SH (2018) The role of NLRP3 inflammasome in stroke and central poststroke pain. Medicine (Baltimore) 97(33): e11861.

22. Bruehl S, Chung OY, Jirjis JN, Biridepalli S (2005) Prevalence of clinical hypertension in patients with chronic pain compared to nonpain general medical patients. Clin J Pain. 21(2): 147-153.

23. Meller T, Stiehm F, Malinowski R, K Thieme (2016) Baroreflexsensitivität und chronischer Schmerz. Der Schmerz 30(5): 470-476. 